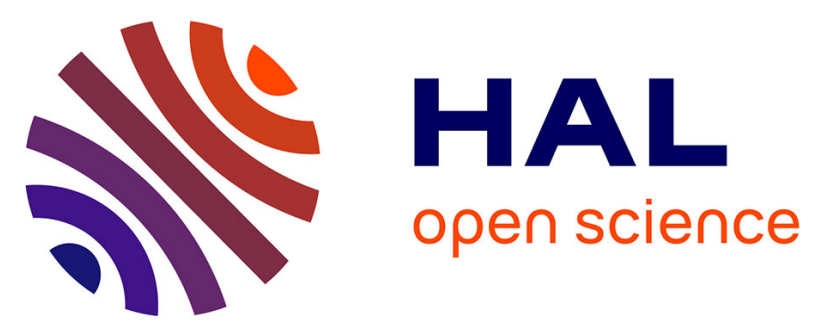

\title{
Temocillin versus carbapenems for urinary tract infection due to ESBL-producing Enterobacteriaceae: a multicenter matched case-control study.
}

Tristan Delory, Simon Gravier, Diane Le Pluart, Géraldine Gaube, Soline Simeon, Benjamin Davido, Emilie Piet, Raphaël Lepeule, Philippe Lesprit, Matthieu Lafaurie

\section{To cite this version:}

Tristan Delory, Simon Gravier, Diane Le Pluart, Géraldine Gaube, Soline Simeon, et al.. Temocillin versus carbapenems for urinary tract infection due to ESBL-producing Enterobacteriaceae: a multicenter matched case-control study.. International Journal of Antimicrobial Agents, In press, 10.1016/j.ijantimicag.2021.106361 . hal-03238476

\section{HAL Id: hal-03238476 \\ https://hal.sorbonne-universite.fr/hal-03238476}

Submitted on 27 May 2021

HAL is a multi-disciplinary open access archive for the deposit and dissemination of scientific research documents, whether they are published or not. The documents may come from teaching and research institutions in France or abroad, or from public or private research centers.
L'archive ouverte pluridisciplinaire HAL, est destinée au dépôt et à la diffusion de documents scientifiques de niveau recherche, publiés ou non, émanant des établissements d'enseignement et de recherche français ou étrangers, des laboratoires publics ou privés. 


\section{TITLE PAGE}

Temocillin versus carbapenems for urinary tract infection due to ESBL-producing Enterobacteriaceae: a multicenter matched case-control study.

\section{AUTHORS:}

Tristan DELORY ${ }^{\mathrm{a}, \mathrm{b}}$, Simon GRAVIER ${ }^{\mathrm{a}, \mathrm{c}}$, Diane LE PLUART ${ }^{\mathrm{d}}$, Géraldine GAUBE ${ }^{\mathrm{e}}$, Soline SIMEON ${ }^{\dagger}$, Benjamin DAVIDO ${ }^{\dagger}$, Emilie PIET ${ }^{g}$, Raphaël LEPEULE ${ }^{e}$, Philippe LESPRIT ${ }^{d}$, Matthieu LAFAURIE ${ }^{\text {a }}$

\section{Tristan DELORY and Simon GRAVIER contributed equally to this manuscript.}

\section{AFFILIATIONS :}

a) APHP, Infectious diseases, and tropical medicine department, Saint-Louis Hospital, F75010, Paris, France

b) Sorbonne Université, INSERM, Institut Pierre Louis d'Épidémiologie et de Santé Publique, IPLESP, F75012, Paris, France

c) Infectious diseases department, Hôpitaux Civils de Colmar, F68000, Colmar, France

d) Unité transversale d'hygiène et d'infectiologie, Service de biologie Clinique, Hôpital Foch, Suresnes, F92150, France

e) APHP, Unité transversale de traitement des infections, Département de prevention diagnostic et de traitement des infections, Hôpital Henri-Mondor, F94000, Créteil, France

f) APHP, Infectious diseases and tropical medicine department, Raymond-Poincaré, Hospital, F92380, Garches, France

g) Infectious diseases department, Annecy-Genevois hospital, F74370, Epagny-MetzTessy, France

RUNNING TITLE (40/40): Temocillin vs. carbapenems for UTI

\section{CORRESPONDING AUTHOR:}

Dr Tristan Delory (TD), delory.tristan@gmail.com

AP-HP, Hôpital Saint-Louis, Service de Maladies Infectieuses et Tropicales

1 avenue Claude Vellefaux, 75010 Paris, France

+33 (0) 620877435

Present address :

Hôpital Annecy-Genevois (CHANGE), Délégation à la Recherche Clinique et l'Innovation 1 avenue de l'hôpital, 74370 Epagny-Metz-Tessy, France 


\section{ALTERNATE CORRESPONDING AUTHOR:}

34 Dr Matthieu Lafaurie (ML): matthieu.lafaurie@aphp.fr

35 AP-HP, Hôpital Saint-Louis, Service de Maladies Infectieuses et Tropicales

361 avenue Claude Vellefaux, 75010 Paris, France 


\section{ABSTRACT}

Objectives: We aim to compare the efficacy of temocillin to carbapenems for ESBL-E UTI.

Methods: We conducted a multicenter retrospective case-control study of adults with ESBLE UTI between January-2015 and October-2019. Cases received temocillin $\geq 50 \%$ of the effective antibiotic therapy duration. Control exclusively received carbapenem. They were statistically matched (1:1 ratio) on period, sex, and age. The clinical cure at the end of antibiotic therapy was analyzed using conditional logistic regression.

Results: We matched 72 temocillin cases to 72 carbapenem controls. Most (67\%) were male, aged 69.4-years in median, 81 (56\%) were immunocompromised, including 44 (31\%) solid organ transplant recipients (SOT). There was no difference between cases and controls for baseline characteristics and microorganisms involved: K.pneumoniae in 59 (41\%), E.coli in 57 (40\%), and Enterobacter spp. in 24 (17\%). The median time from admission to effective antibiotic therapy was 0-days [0-2]. Among cases, first-line antibiotic therapy ( $\leq 72$ hours) was temocillin in 6 (8\%) and carbapenems in 39 (54\%). Temocillin was given at the median daily dose of $4 \mathrm{~g}$ [2-4], after 3-days [2-5] of carbapenems. Patients received temocillin for $81 \%$ [7093] of the effective antibiotic course duration during 11-days [8-14]. The effective antibiotic duration was similar in cases and controls ( $p$-value $=0.067$ ). Clinical cure at the end of the antibiotic therapy was $94 \%(68 / 72)$ in cases versus $99 \%(71 / 72)$ in controls ( $p$-value=0.206), without difference among immunocompromised and SOT patients ( $p$-value>0.050).

Conclusions: Temocillin effectively relays beta-lactams, including carbapenems, for the treatment of (complicated) ESBL-E UTI. Its efficacy is consistent among kidney transplant recipients.

\section{KEYWORDS (5)}

Temocillin, Carbapenems, Urinary Tract Infection, ESBL, Case-control study.

\section{ABBREVIATIONS}

BSAC: The British Society for Antimicrobial Chemotherapy

CA-SFM: Comité de l'Antibiogramme de la Société Française de Mircrobiologie 95\% $\mathrm{Cl}: 95 \%$ confidence interval

EOT: end of the antibiotic therapy 
68 EUCAST: the European Committee on Antimicrobial Susceptibility Testing

69 IDSA: Infectious Disease Society of America

70 IQR: interquartile range

71 (a)OR: (adjusted) Odds Ratio

72 SOT: Solid organ transplant

73 STROBE: Strengthening the Reporting of Observational Studies in Epidemiology

74 UTI: Urinary tract infection 


\section{ARTICLE}

\section{INTRODUCTION}

For decades, the gold-standard antibiotic regimen in ESBL-producing Enterobacteriaceae (ESBL-E) infections has been carbapenem. Few trials explored alternatives to carbapenem in patients with severe infections due to ESBL-E. The MERINO trial showed that piperacillintazobactam was not non-inferior to meropenem for 30-day mortality among patients with bloodstream infection and ceftriaxone resistance [1]. Much investigations to explore new options are needed [2-4].

Urinary tract infection (UTI) is the leading cause of infection due to gram-negative bacteria in primary care and hospital settings [2]. ESBL-producing strains are frequently involved in UTI, and temocillin appears as a possible intravenous alternative to carbapenem in such settings $[5,6]$.

Temocillin is active against Enterobacteriaceae and is stable against hydrolysis by ESBLs and AmpC $\beta$-lactamases. Since 1985, eleven small-size studies have reported on temocillin efficacy in mixed definitions of UTI [6-15]. According to the susceptibility breakpoint, its efficacy correlates with higher doses, ranging from $2 \mathrm{~g}$ bid or tid [16]. Six surveys used temocillin doses below $4 \mathrm{~g}$ per day, and none investigated temocillin efficacy with an active comparator, including carbapenems or others antibiotics.

Three prospective studies have been initiated over the last years (NCT03543436, NCT02681263, and NCT01543347), including one non-inferiority open-label randomized trial comparing temocillin to carbapenems. However, as of today, they failed to enrolled patients, and some were terminated. Pending trials' results, many physicians started to treat patients with temocillin and collected small sets of observations.

We conducted a multi-centric matched case-control study to provide reliable data regarding temocillin efficacy as an alternative to carbapenems in urinary tract infection due to ESBL-E. 


\section{MATERIALS AND METHODS}

\subsection{Study design and settings}

\subsubsection{Study design}

We conducted a multi-centric case-control study across six French participating tertiary-level hospitals. We detail study sites in supplementary Table A.1.

\subsubsection{Selection of cases and controls}

Consecutive adults hospitalized between January 2015 and October 2019 for a definite UTI diagnosis due to an ESBL-producing Enterobacteriaceae (ESBL-E) susceptible to carbapenems were eligible for the study. They were not opposed to retrospective data collection. We defined a definite UTI as a positive urine culture with $\geq 10^{3} \mathrm{CFU} / \mathrm{mL}$ of a single ESBL-E strain, and two of the following signs or symptoms [17]: chills or fever (temperature $>38^{\circ} \mathrm{C}$ ), flank or pelvic pain, nausea, or vomiting, dysuria, urinary frequency, or urinary urgency, costovertebral angle pain.

Cases had received temocillin above $50 \%$ of the time of effective antibiotic therapy duration. Temocillin was given as first-line therapy or after a maximum of 72 hours of other antibiotics effective against the ESBL-producing strain, including carbapenems and aminoglycosides. The ESBL-producing strain causing the UTI had to be sensitive to temocillin and carbapenems, according to the guidelines from the French microbiology society ("Comite de I'Antibiogramme de la Société Française de Microbiologie", CA-SFM) [18].

Controls had exclusively received carbapenem (imipenem, or meropenem, or ertapenem) as first-line therapy or after a maximum of 72 hours of other effective antibiotics, including aminoglycosides. The ESBL-producing strain causing the UTI had to be sensitive to carbapenems, according to the CA-SFM guidelines [18].

The physician in charge defined the modalities of the antibiotic regimen, including dosage and its adaptation to the renal function when appropriate, route of administration, and the treatment duration. We identified patients using the electronic database of the microbiology department of each participating site. The local study team performed manual screening for inclusion / non-inclusion criteria. Data were retrieved from patient medical charts using standardized case report forms. Cases were matched to controls at a 1:1 ratio, using a statistical matching (1-point caliper) by 6 -month period, sex, and age.

\subsubsection{Study endpoints}

The primary efficacy endpoint was the clinical cure at the end of the antibiotic therapy (EOT). We adapted the clinical cure definition from the FDA guidelines, as the resolution of fever 
133 (temperature $\leq 38^{\circ} \mathrm{C}$ ) and UTI symptoms without the occurrence of new UTI symptoms and 134 the absence of clinical or microbiological failure [17]. We defined clinical or microbiological failure as the non-resolution of fever (temperature $>38^{\circ} \mathrm{C}$ ) or symptoms of $\mathrm{UTI}$, or new symptoms of UTI, or all-cause death, or positive urine culture yielding $\geq 10^{3} \mathrm{CFU} / \mathrm{mL}$ of the same uropathogen to that identified at antibiotic initiation, at any time from initiation to EOT. Urinalysis and blood culture at EOT was not mandatory and let to physician discretion.

Secondary efficacy endpoints were the length of hospital stay and UTI relapse to the same ESBL-E strain within three months from the first day of effective antibiotic therapy.

141 Safety endpoints were Clostridium difficile infection, loss to follow-up, re-hospitalization, and all-cause death within three months from the first day of effective antibiotic therapy.

\subsection{Compliance with research ethics standards}

The institutional review board (IRB) $n^{\circ} 0011642$, of the French society of infectious diseases (SPILF), approved the study protocol under the number 2018-0503. This multi-centric observational study was registered to the French authorities using the MR-004 referral methodology of the "Commission Nationale de I'Informatique et des Libertés" (CNIL) under the number MR004-2205982 (Annecy-Genevois hospital). The data collection process was in line with the European General Data Protection Regulation. ClinicalTrials.gov number, NCT04671290.

\subsection{Statistical analyses}

152 Patients' characteristics, primary and secondary endpoints, were described using descriptive 153 statistics including frequencies and percentages, median, and interquartile range [IQR]. We 154 tabulated patients' characteristics, the occurrence of primary and secondary endpoints, by patient status (case or control). Then, we computed the strength of association with primary and secondary endpoints using conditional logistic regression adjusted on the study arm. We report associations as odds ratio (OR) with 95\% confidence intervals $(\mathrm{Cl})$. All tests were twotailed, at $5 \%$ bilateral for significance. We performed data curation and statistical analyses using the $\mathrm{R}$ version 4.0.1 (R Foundation for Statistical Computing, Vienna, Austria). We reported the results following the Strengthening the Reporting of Observational Studies in Epidemiology (STROBE) statement [19]. 


\section{RESULTS}

\subsection{Patients characteristics}

We retrospectively enrolled 144 patients (72 cases and 72 controls) among 183 patients screened (supplementary Figure B.1). Most of the enrolled patients (67\%) were men, half were aged 69 years and above, and half were presenting a high Charlson score value of at least four. The median creatinine clearance (MDRD) was $42.2 \mathrm{ml} / \mathrm{min} / 1.73 \mathrm{~m}^{2}$ [interquartile range (IQR), 24.5 to 82.3 ], and a third (31\%) of patients were kidney transplant recipients. All but eight patients had complicated UTI, and 57 (40\%) required urinary catheterization, including 34 (24\%) double-J stent [17]. Microorganisms involved in UTI were similar between cases and controls: K. pneumoniae in 59 (41\%), E. coli in 57 (40\%), Enterobacter spp. in $24(17 \%)$, and others in $4(2 \%)$. A third of patients had bloodstream infections associated with UTI. Table 1 describes the patients' characteristics at hospital admission.

\subsubsection{Initial antibiotic therapy}

The first-line antibiotic therapy was more appropriate among cases (75\%) than controls $(53 \%)(p$-value $=0.006)$. The time to appropriate antibiotic therapy was shorter in cases than in controls $(\mathrm{OR}=0.71(95 \% \mathrm{Cl}, 0.56$ to 0.90$), p$-value $=0.005)$.

\subsubsection{Temocillin, cases}

Among the 72 temocillin cases, half $(54 \%)$ received carbapenems over the first 72 antibiotic therapy hours. Only six $(8 \%)$ received temocillin as first-line antibiotic therapy. Other first-line antibiotics are described in supplementary Table A.2. The switch from the first-line antibiotic to temocillin occurred after a median of 3 days [IQR, 2 to 5] of the first-line antibiotic. It was for sparing piperacillin/tazobactam in eight patients, for sparing carbapenems in 63, and because of carbapenems' allergy in one. Temocillin was adapted to creatinine clearance at the median daily dose of $4 \mathrm{~g}$ [IQR, 2 to 4], ranging from a minimum of $0.5 \mathrm{~g}$ per day to a maximum of $6 \mathrm{~g}$ per day. Twenty-nine received $2 \mathrm{~g}$ per day or less, and seven received $6 \mathrm{~g}$ per day. It was given for a median of 11 days [IQR, 8 to 14] and accounted for $81 \%$ [IQR, $70 \%$ to $93 \%$ ] of the antibiotic course's total duration. Seven (10\%) patients received temocillin as a prolonged infusion. Fourteen (19\%) patients received temocillin over the effective antibiotic therapy duration, including two with bloodstream infection. The median MIC to temocillin was $6 \mathrm{mg} / \mathrm{I}$ [IQR, 4 to 8], ranging from a minimum of $2 \mathrm{mg} / \mathrm{l}$ to a maximum of $16 \mathrm{mg} / \mathrm{l}$.

\subsubsection{Carbapenems, controls}


Among the 72 controls, $33(46 \%)$ received empirical carbapenem. Others had carbapenem after a median of 1 day [IQR, 0 to 3] from the start of first-line antibiotic therapy. The MIC to carbapenem was not available. The first carbapenem received was imipenem in 48 (68\%), meropenem in $3(4 \%)$, and ertapenem in 20 (28\%). Twenty-two patients switched to ertapenem, 20 initially receiving imipenem and two meropenem. In addition to IV betalactams, controls received 4 times lower infusion of aminoglycosides (4\%) than cases (15\%) $(p$-value $=0.035)$.

\subsubsection{Duration of effective antibiotic therapy}

The overall duration of effective antibiotic therapy was long at 15 days [IQR, 12 to 18] and was similar between cases (14 days) and controls (16 days) ( $p$-value $=0.067$ ). Solid organ transplant recipients had a prolonged course of effective antibiotic therapy (18 days).

Sixty (42\%) patients completed their antibiotic therapy in the hospital, while the others (58\%) were discharged earlier after a median of 7 days. The latters received additional parenteral antibiotic treatment for a median of 8 days. Early discharge was more frequent in the carbapenem group (69\%) than in the temocillin group (47\%).

\subsection{Clinical cure at the end of antibiotic therapy}

Table 2 describes the associations with the occurrence of the primary endpoint. The rate of clinical cure at EOT (primary endpoint) was similar between cases (94\%) and controls (99\%), even after adjustment on the appropriateness of antibiotic therapy at baseline, aOR=4.11 $(95 \% \mathrm{Cl}, 0.02$ to 1.64$), p$-value $=0.125$. In bivariate analysis, there was also no difference for primary endpoint among those who received initial administration of aminoglycosides, those who were immunocompromised or solid organ (kidney) transplant recipients, nor for any of the possible confounding variables. Among patients who received temocillin, the previous carbapenem administration was not increasing the clinical cure at EOT $(\mathrm{OR}=0.7(95 \% \mathrm{Cl}$, 0.09 to 5.27$), p$-value $=0.729$ ). The 14 patients who received standalone temocillin for effective antibiotic therapy were all cured at EOT.

\subsection{Secondary and safety endpoints}

Table 3 describes the occurrence of secondary and safety endpoints. The length of stay at hospital stay was similar between cases and controls, as were the rate of relapse of UTI, rehospitalization, Clostridium difficile infections, loss to follow-up, and mortality. Among 17 patients who received temocillin and had a UTI relapse, we identified the same pathogen in $15(88 \%)$. Ten had susceptibility testing for temocillin, and three $(30 \%)$ were resistant, supplementary Table A.3. Among 16 patients who received carbapenems and had a UTI 
227 relapse, 10 (63\%) were involving the same pathogen. Of the 33 patients with UTI relapse, 24

228 had a strain tested for carbapenem susceptibility, and none was resistant.

229 The median time from antibiotic start to all-cause death was 72 days [IQR, 28 to 93]. Only 230 one death occurred under antibiotic therapy. This patient received three days of imipenem 231 followed by five days of temocillin. According to the Charlson score, patients who died had a 232 median 1-year probability of death above $85 \%$ at the time of antibiotic start, while it was $52 \%$ 233 in others. The supplementary Table A.4. details the characteristics of deceased patients. 
In this multi-centric matched case-control study of adults receiving antibiotics for a (complicated) UTI due to ESBL-producing Enterobacteriaceae, the clinical cure rate at the end of the antibiotic therapy was very high (97\%). It was similar between patients who mostly received temocillin (94\%) than those who received only carbapenem (99\%). These results were consistent in immunocompromised patients, including solid organ (kidney) transplant recipients.

The very high clinical cure rate in patients managed with temocillin (94\%) was independent of the microorganism or the patients' characteristics. Temocillin was used to relay an appropriate empirical antibiotic therapy, at the standard daily dose of $4 \mathrm{~g}$ per day or adapted to creatinine clearance, in infection involving pathogens with MIC $\leq 8 \mathrm{mg} / \mathrm{l}$. Interesting findings, considering that most $(60 \%)$ of the strains involved were not $E$. coli, and that a third of patients were bacteremic or kidney transplant recipients. Other alternatives such as cefoxitin or piperacillin/tazobactam suffer this comparison, especially in patients with bacteremic UTI involving $K$. pneumoniae [1,2,20]. A retrospective cohort showed a clinical success rate without relapse of $74 \%$, comparable to that of carbapenems $(81 \%)$, among male patients with UTI due to ESBL-producing E. coli treated with cefoxitin [21]. Other studies were in patients with nonsevere infections, suggesting reserving its use in these conditions [4]. The INCREMENT-SOT international cohort showed that in bacteremia secondary to UTI in kidney transplant recipients patients receiving $\beta$-lactam/ $\beta$-lactamase inhibitors (BLIBLIs), the cure at day 30 was $87 \%$ [22]. Despite a small sample size, there was no difference between those who received monotherapy versus combination therapies or carbapenem monotherapy [22]. Even if data shows efficacy for new BLIBLIs (ceftolozantazobactam or ceftazidime-avibactam) in comparable settings, their activity against extensively drug-resistant organisms underlines the need to reserve these drugs for such microorganisms [4]. Data for other antibiotics, including oxyiminocephalosporins, amiglyocides, tigecycline, or fosfomycin, are either negative, scarce, contradictory, or in favor of a lower benefit/risk balance. Their use is therefore not yet recommended as a definite antibiotic therapy [4].

Recently, a Belgian study reported 152 implementations of OPAT services. It showed that $98 \%$ of patients discharged with monotherapy of temocillin $4 \mathrm{~g}$ per day were cured [7]. It suggests that in UTI due to ESBL-E, an analysis of the cost-effectiveness of OPAT based on ertapenem versus temocillin could be of interest.

In addition to our data, the previous results of the eleven studies on temocillin showed a pooled efficacy of $89 \%(95 \% \mathrm{Cl}, 83 \%$ to $97 \%$, Figure 1) for treatment with temocillin, varying 
by type of UTI [6-15]. However, temocillin is undoubtedly not a golden bullet for carbapenem sparing, as its efficacy is predicted to range from $66 \%$ to $97 \%$. Temocillin was mainly given after three days of adequate antibiotic therapy (including carbapenem) in patients with MIC $\leq 8 \mathrm{mg} / \mathrm{l}$. If temocillin was efficient and safe in a relay, its use in empirical treatment might be challenging when considering the sensitivity (i.e., the MIC) of the pathogen [5]. Indeed, there is a lack of consensus for MIC breakpoints in UTI. The British Society for Antimicrobial Chemotherapy (BSAC) is considering $8 \mathrm{mg} / \mathrm{l}$ in systemic infection and $32 \mathrm{mg} / \mathrm{l}$ in UTI, while the European Committee on Antimicrobial Susceptibility Testing (EUCAST) is considering 16 $\mathrm{mg} / \mathrm{l}$ in both situations $[5,23,24]$. Over the study period, the CA-SFM considered $8 \mathrm{mg} / \mathrm{l}$ in both cases and is now aligned on EUCAST [18]. According to MIC, microorganisms, clinical situations, and local epidemiology, we can expect that only $3 \%$ to $51 \%$ (MIC $\leq 8 \mathrm{mg} / \mathrm{l}$ ) to $58 \%$ to $94 \%$ (MIC $\leq 16 \mathrm{mg} / \mathrm{l}$ ) of ESBL-E will be sensitive to temocillin [5,25-28]. Harmonized and reliable susceptibility breakpoints will therefore be needed to generalize the use of temocillin [5]. If the EUCAST threshold were to be used, a daily dose of $6 \mathrm{~g}$ would be required to ensure temocillin efficacy [16]. Nevertheless, we documented three cases of emerging resistance to temocillin among patients who presented relapses of UTI. Two received $6 \mathrm{~g}$ per day of temocillin. Close monitoring of patients treated with temocillin is therefore necessary.

Our study suffers limitations. First, the retrospective design, the sample size, and the small number of events limited the statistical power to manage confounding factors [29]. Second, the extensive use of carbapenem in the first line yielded a selection of the population and biased measurement of point estimates. Only randomization can prevent such biases. Nevertheless, the large trials initiated are failing to enroll patients, answers are needed, and real-life data are of interest in this context. To ensure proper analysis, we used a multi-centric design, with a 1:1 ratio for matching, which is assumed to provide sufficient statistical power for a crude estimation of the primary endpoint [30]. We used a validated definition for the primary endpoint and collected mid-range secondary endpoints three months after the start of effective antibiotic therapy. But urinalysis and blood culture at the end of antibiotic treatment was not mandatory. We also enrolled a population at high risk of antibiotic therapy failure, including immunocompromised and solid organ (kidney) transplant recipients and chronic kidney disease patients [2]. The high efficacy of temocillin in this subset of patients was not reduced, which is also reinsuring.

\section{CONCLUSION}

Temocillin is effective and safe in the relay of beta-lactams, including carbapenems for treating (complicated) UTI due to ESBL-producing Enterobacteriaceae. Its efficacy is consistent in immunocompromised, including in kidney transplant recipients. However, the 
304 risk of emerging resistance stresses the need for close monitoring. A randomized 305 comparison to carbapenems is warranted. 
307 Acknowledgments: This work was selected to be presented at the 30th European Congress 308 on Clinical Microbiology and Infectious Diseases (ECCMID) - 2020. It is registered in the 309 30th ECCMID 2020, abstract book, under the number 3172.

310 We thank the clinical research and the microbiology team of every participating site, 311 especially the Annecy-Genevois hospital team, for technical assistance.

312 Funding: This research did not receive any specific grant from funding agencies in the 313 public, commercial, or not-for-profit sectors.

314 Conflict of interest: None to declare.

315 Access to data: Academic researchers can access the data for 12 months after the 316 publication of results. Transfer to countries outside of the EU is not allowed. A formal request 317 had to be sent to the corresponding author.

318 Contribution: Conceptualization: T.D., S.G., and M.L. Methodology: T.D. Validation: T.D., 319 S.G., M.L., and P.L. Formal Analysis: T.D. Investigation: S.G., D.L-P., G.G., S.S., E.P., B.D., 320 R.L., P.L., and M.L. Data Curation: T.D. and S.G. Writing - Original Draft Preparation: T.D. 321 Writing - Review \& Editing: T.D., S.G., D.L-P., G.G., S.S., E.P., B.D., R.L., P.L., and M.L. 322 Supervision: M.L. Project Administration: T.D., S.G., and M.L. 


\section{REFERENCES}

[1] Harris PNA, Tambyah PA, Lye DC, Mo Y, Lee TH, Yilmaz M, et al. Effect of PiperacillinTazobactam vs Meropenem on 30-Day Mortality for Patients With E coli or Klebsiella pneumoniae Bloodstream Infection and Ceftriaxone Resistance: A Randomized Clinical Trial. JAMA 2018;320:984-94. https://doi.org/10.1001/jama.2018.12163.

[2] Wagenlehner FME, Bjerklund Johansen TE, Cai T, Koves B, Kranz J, Pilatz A, et al. Epidemiology, definition and treatment of complicated urinary tract infections. Nat Rev Urol 2020;17:586-600. https://doi.org/10.1038/s41585-020-0362-4.

[3] Gutiérrez-Gutiérrez B, Rodríguez-Baño J. Current options for the treatment of infections due to extended-spectrum beta-lactamase-producing Enterobacteriaceae in different groups of patients. Clin Microbiol Infect 2019;25:932-42. https://doi.org/10.1016/j.cmi.2019.03.030.

[4] Rodríguez-Baño J, Gutiérrez-Gutiérrez B, Machuca I, Pascual A. Treatment of Infections Caused by Extended-Spectrum-Beta-Lactamase-, AmpC-, and Carbapenemase-Producing Enterobacteriaceae. Clin Microbiol Rev 2018;31. https://doi.org/10.1128/CMR.00079-17.

[5] Balakrishnan I, Koumaki V, Tsakris A. Temocillin: is this the right momentum for its global use? Future Microbiol 2019;14:81-3. https://doi.org/10.2217/fmb-2018-0316.

[6] Balakrishnan I, Awad-El-Kariem FM, Aali A, Kumari P, Mulla R, Tan B, et al. Temocillin use in England: clinical and microbiological efficacies in infections caused by extendedspectrum and/or derepressed AmpC $\beta$-lactamase-producing Enterobacteriaceae. J Antimicrob Chemother 2011;66:2628-31. https://doi.org/10.1093/jac/dkr317.

[7] Quintens C, Steffens E, Jacobs K, Schuermans A, Van Eldere J, Lagrou K, et al. Efficacy and safety of a Belgian tertiary care outpatient parenteral antimicrobial therapy (OPAT) program. Infection 2020;48:357-66. https://doi.org/10.1007/s15010-020-013984.

[8] Asbach HW, Becker-Boost E, Melekos MD. Clinical evaluation of temocillin in urinary tract infections. Drugs 1985;29 Suppl 5:175-7. https://doi.org/10.2165/00003495$198500295-00037$.

[9] Kosmidis J. The treatment of complicated and uncomplicated urinary tract infections with temocillin. Drugs 1985;29 Suppl 5:172-4. https://doi.org/10.2165/00003495198500295-00036.

[10] Schulze B, Heilmann HD. Treatment of severe infections with temocillin. Clinical and bacteriological evaluation. Drugs 1985;29 Suppl 5:207-9. https://doi.org/10.2165/00003495-198500295-00046.

[11] Alexandre K, Leysour de Rohello F, Dahyot S, Etienne M, Tiret I, Gillibert A, et al. Efficacy of temocillin against MDR Enterobacterales: a retrospective cohort study. J Antimicrob Chemother 2021;76:784-8. https://doi.org/10.1093/jac/dkaa486.

[12] Frankard J, Byl B, Rodriguez-Villalobos C, Mélot C, Vincent J-L, Struelens M, et al. Clinical presentation and outcome of multi-resistant Enterobacter aerogenes infections: a review of 116 episodes. Clinical Microbiology and Infection 2004;10:379.

[13] Laterre P-F, Wittebole X, Van de Velde S, Muller AE, Mouton JW, Carryn S, et al. Temocillin ( $6 \mathrm{~g}$ daily) in critically ill patients: continuous infusion versus three times daily administration. J Antimicrob Chemother 2015;70:891-8. https://doi.org/10.1093/jac/dku465.

[14] Gupta ND, Smith RE, Balakrishnan I. Clinical efficacy of temocillin. J Antimicrob Chemother 2009;64:431-3. https://doi.org/10.1093/jac/dkp208.

[15] Heard KL, Killington K, Mughal N, Moore LSP, Hughes S. Clinical outcomes of temocillin use for invasive Enterobacterales infections: a single-centre retrospective analysis. JAC-Antimicrobial Resistance 2021;3. https://doi.org/10.1093/jacamr/dlab005.

[16] Giske CG, Kahlmeter G, MacGowan A, Turnidge J, on behalf of the EUCAST Steering Committee. Comment on: Efficacy of temocillin against MDR Enterobacterales: a retrospective cohort study. Journal of Antimicrobial Chemotherapy 2021. https://doi.org/10.1093/jac/dkab081. 
[17] Food and Drug Administration. Complicated Urinary Tract Infections: Developing Drugs for Treatment Guidance for Industry 2018.

[18] CASFM / EUCAST : Société Française de Microbiologie Ed ; 2018: p37, n.d.

[19] Vandenbroucke JP, von Elm E, Altman DG, Gøtzsche PC, Mulrow CD, Pocock SJ, et al. Strengthening the Reporting of Observational Studies in Epidemiology (STROBE): explanation and elaboration. PLoS Med 2007;4:e297. https://doi.org/10.1371/journal.pmed.0040297.

[20] Pangon B, Bizet C, Buré A, Pichon F, Philippon A, Regnier B, et al. In vivo selection of a cephamycin-resistant, porin-deficient mutant of Klebsiella pneumoniae producing a TEM-3 beta-lactamase. J Infect Dis 1989;159:1005-6. https://doi.org/10.1093/infdis/159.5.1005.

[21] Senard O, Lafaurie M, Lesprit $P$, Nguyen $Y$, Lescure $X$, Therby A, et al. Efficacy of cefoxitin versus carbapenem in febrile male urinary tract infections caused by extended spectrum beta-lactamase-producing Escherichia coli: a multicenter retrospective cohort study with propensity score analysis. Eur J Clin Microbiol Infect Dis 2020;39:121-9. https://doi.org/10.1007/s10096-019-03701-0.

[22] Pierrotti LC, Pérez-Nadales E, Fernández-Ruiz M, Gutiérrez-Gutiérrez B, Tan BH, Carratalà $J$, et al. Efficacy of $\beta$-lactam $/ \beta$-lactamase inhibitors to treat extended-spectrum beta-lactamase-producing Enterobacterales bacteremia secondary to urinary tract infection in kidney transplant recipients (INCREMENT-SOT Project). Transpl Infect Dis 2020:e13520. https://doi.org/10.1111/tid.13520.

[23] EUCAST: Clinical breakpoints and dosing of antibiotics n.d. https://www.eucast.org/clinical_breakpoints/ (accessed October 4, 2020).

[24] Vanstone GL, Dilley R, Schwenk S, Williams A, Balakrishnan I. Temocillin disc diffusion susceptibility testing by EUCAST methodology. J Antimicrob Chemother 2013;68:26889. https://doi.org/10.1093/jac/dkt248.

[25] Kuch A, Zieniuk B, Żabicka D, Van de Velde S, Literacka E, Skoczyńska A, et al. Activity of temocillin against ESBL-, AmpC-, and/or KPC-producing Enterobacterales isolated in Poland. Eur J Clin Microbiol Infect Dis 2020;39:1185-91. https://doi.org/10.1007/s10096-020-03844-5.

[26] Ip M, Lai CK, Fung KSC, Wong K-T, Zhu C, Van de Velde S, et al. Activity of temocillin and 15 other agents, including fosfomycin and colistin, against Enterobacteriaceae in Hong Kong. Eur J Clin Microbiol Infect Dis 2017;36:2491-4. https://doi.org/10.1007/s10096-017-3091-8.

[27] Rahbar M, Van de Velde S, Eslami P, Mardani M. Activity of temocillin and comparators against urinary Escherichia coli and Klebsiella pneumoniae from Iran. Eur J Clin Microbiol Infect Dis 2020;39:1793-6. https://doi.org/10.1007/s10096-020-03898-5.

[28] Tsakris A, Koumaki V, Politi L, Balakrishnan I. Activity of temocillin against KPCproducing Enterobacteriaceae clinical isolates. Int J Antimicrob Agents 2020;55:105843. https://doi.org/10.1016/j.ijantimicag.2019.10.024.

[29] Dupont WD. Power Calculations for Matched Case-Control Studies. Biometrics 1988;44:1157-68. https://doi.org/10.2307/2531743.

[30] Rodrigues L, Kirkwood BR. Case-control designs in the study of common diseases: updates on the demise of the rare disease assumption and the choice of sampling scheme for controls. Int J Epidemiol 1990;19:205-13. https://doi.org/10.1093/ije/19.1.205. 